were compared between cases belonging to one of the hospitals and 2 control groups of YORA and EORA patients of the same center, matched by sex, diagnosis date \pm 2 years, RF and / or ACPA status and presence of erosions in baseline $R x$.

Results: A total of 2790 records of RA patients were analyzed, identifying 59 cases of onset in "very elderly" ( $2 \%$ of the total). Table 1 shows its clinical, analytical characteristics and treatments at diagnosis.

Table 1. Demographic and clinical data of the 59 VEORA patients

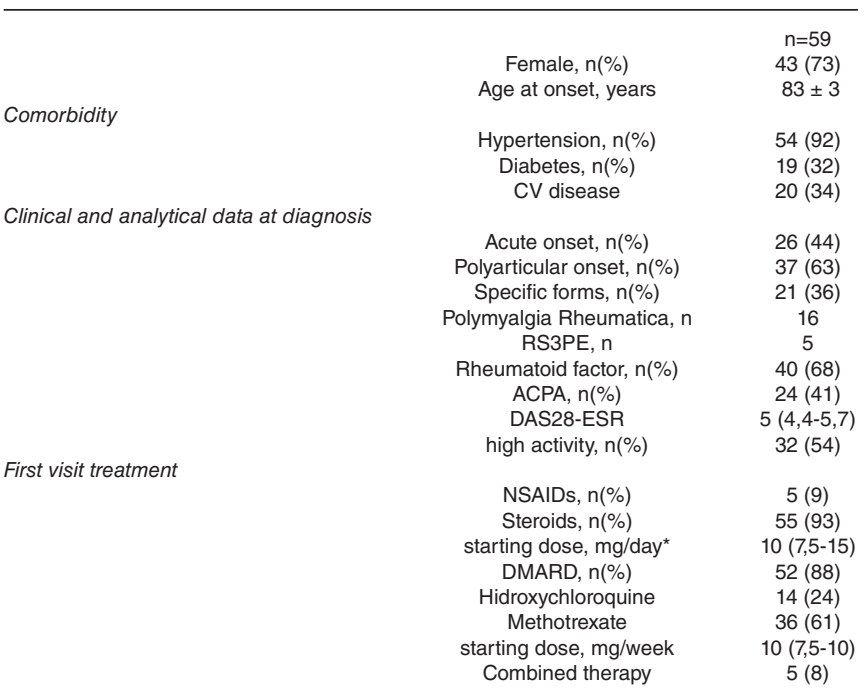

DAS28-ESR and the number of patients in remission or low activity at one year showed no differences between EORA and VEORA, or between these groups and that of younger patients.

Elderly patients (EORA and VEORA), compared with YORA, presented with higher frequency hypertension and $C V$ disease, higher elevation in acute phase reactants at the onset and disease activity at diagnosis. VEORA patients, compared to EORA, showed a higher frequency of dyslipidemia $(p=$ 0.04). There were also no significant differences between VEORA and EORA in the distribution and type of joints affected, time to diagnosis, acute phase reactants or disease activity at the onset. A higher frequency of special forms (such as PMR or RS3PE) was close to statistical significance in the VEORA group $(p=0.054)$.

Regarding initial treatment, both EORA and VEORA received steroidal treatment more frequently and a lower dose of Methotrexate during the first year. Biological treatments was also significantly higher in YORA $(p=0,000)$. When comparing VEORA and EORA, differences related to the use of NSAIDs were found, lower in VEORA ( $p=0.000)$, as well as in the maximum dose of Methotrexate reached in the next 12 months, higher in the EORA group $(p=0.01)$. No differences in adverse events with DMARDs were observed.

Conclusion: There have been few differences in the comorbidity profile and clinical characteristics at the onset between VEORA and EORA patients. Despite the differences observed in its management (more conservative in EORA and VEORA vs YORA, and in VEORA vs EORA), we have not observed differences in DAS28-ESR activity after one year.

Disclosure of Interests: Alicia García Dorta: None declared, Cristina Almeida: None declared, Hernández Díaz Marta: None declared, Laur Cáceres Martín: None declared, Elisa Trujillo: None declared, Carlos Rodríguez-Lozano: None declared, Iván Ferraz-Amaro Grant/research support from: Pfizer, Abbvie, Speakers bureau: Pfizer, Abbvie, MSD., Juan Carlos Quevedo-Abeledo Speakers bureau: Abbvie

DOI: 10.1136/annrheumdis-2020-eular.6344

\section{SAT0077 CARDIOVASCULAR RISK ASSESSMENT WITH CAROTID ULTRASONOGRAPHY IN ADDITION TO THE TRADITIONAL CARDIOVASCULAR RISK FACTORS IN RHEUMATOID ARTHRITIS PATIENTS: A CASE CONTROL STUDY}

R. Gonzalez Mazario ${ }^{1}$, J. J. Fragio-Gil', P. Martinez Calabuig ${ }^{2}$, E. Grau García ${ }^{1}$, M. De la Rubia Navarro', C. Pávez Perales ${ }^{1}$, S. Leal Rodriguez ${ }^{1}$, I. Martínez Cordellat $^{1}$, J. Ivorra Cortés ${ }^{1}$, R. Negueroles Albuixech ${ }^{1}$, J. E. Oller Rodríguez ${ }^{1}$, L. Gonzalez Puig ${ }^{1}$, C. Alcañiz Escandell ${ }^{1}$, I. Chalmeta Verdejo ${ }^{1}$, F. M. Ortiz Sanjuan ${ }^{1}$, E. Vicens Bernabeu ${ }^{1}$, I. Cánovas Olmos ${ }^{1}$, C. Nájera Herranz ${ }^{1}$, J. A. Román Ivorra'. ${ }^{1}$ Hospital Universitario y Politécnico de La Fe, Rheumatology,
València, Spain; ${ }^{2}$ Universidad Católica de Valencia, Medical School, Valencia, Spain

Background: Cardiovascular disease $(\mathrm{CV})$ is the most frequent cause of death in rheumatoid arthritis (RA) patients. It is well known that RA acts as an independent cardiovascular risk factor.

Objectives: To assess the $\mathrm{CV}$ risk in RA patients using carotid ultrasonography (US) additionally to the traditional $\mathrm{CV}$ risk factors.

Methods: A prospective transversal case control study was performed, including adult RA patients who fulfilled ACR/EULAR 2010 criteria and healthy controls matched according to $\mathrm{CV}$ risk factors. Population over 75 years old, patients with established CV disease and/or chronic kidney failure (from III stage) were excluded. The US evaluator was blinded to the case/control condition and evaluated the presence of plaques and the intima-media thickness. Statistical analysis was performed with $R$ (3.6.1 version) and included a multivariate variance analysis (MANOVA) and a negative binomial regression adjusted by confounding factors (age, sex and CV risk factors).

Results: A total of 200 cases and 111 healthy controls were included in the study. Demographical, clinical and US data are exposed in table 1. Not any difference was detected in terms of $\mathrm{CV}$ risk factors between the cases and controls. In both groups a relationship between age, BMI and high blood pressure was detected $(p<0.001)$.

Table 1.

\begin{tabular}{lcc}
\hline & RA cases & \\
& $\mathrm{n}=200$ & Controls $\mathrm{n}=111$ \\
\hline Age & $60,56(10,71)$ & \\
Sex & Female $163(81,5 \%)$ & $56,79(12,15)$ \\
Smoking status & Male $37(18,5 \%)$ & Female $73(65,77 \%)$ \\
& Active smoker $42(21 \%)$ & Male $38(34,23 \%)$ \\
& No $107(53,5 \%)$ & Active smoker $20(18,02 \%)$ \\
High blood pressure & Ex-smoker $51(25,5 \%)$ & No $71(63,96 \%)$ \\
Diabetes Mellitus & $83(41,5 \%)$ & Ex-smoker $20(18,02 \%)$ \\
Dyslipidemia & $16(8 \%)$ & $34(30,63 \%)$ \\
Daily physical activity & $93(46,5 \%)$ & $9(8,11 \%)$ \\
Family history of CVD & $138(69 \%)$ & $39(35,14 \%)$ \\
BMI & $26(13 \%)$ & $64(57,66 \%)$ \\
Blood pressure & $26,38(5,03)$ & $9(8,11 \%)$ \\
Total cholesterol & $127,2(18,36) / 78,67(10,21)$ & $26,2(5,19)$ \\
cLDL & $197,88(37,17)$ & $127,77(19,42) / 78,28(10,59)$ \\
CT/cHDL & $108,79(34,38)$ & $194,77(35,79)$ \\
Tryglicerides & $3,28(0,97)$ & $114,44(30,93)$ \\
CRP (mg/L) & $119,56(63,83)$ & $3,77(1,05)$ \\
ERS & $5,46(8,5)$ & $121,58(75,08)$ \\
Right/Left carotid cIMT & $20,75(16,58)$ & $2,31(2,32)$ \\
Plaques & $0,78(0,15) / 0,77(0,14)$ & $11,25(7,42)$ \\
Bilateral & $101(50,5 \%)$ & $0,62(0,11) / 0,64(0,12)$ \\
Right carotid & $64(32 \%)$ & $32(28,83 \%)$ \\
Left carotid & $17(8,5 \%)$ & $11(9,91 \%)$ \\
Number of plaques & $20(10 \%)$ & $7(6,31 \%)$ \\
& $1,61(2,16)$ & $14(12,61 \%)$ \\
\hline & & $0,55(1,14)$ \\
& &
\end{tabular}

Table 2. RA basal characteristics

\begin{tabular}{lc}
\hline Disease duration (years) & $16,98(11,38)$ \\
Erosions (X-Ray of hands/feet) & $163(81,5 \%)$ \\
Seropositive (RF/anti-CCP) & $146(73 \%)$ \\
Extra-articular symptoms & $44(22 \%)$ \\
Intersticial difusse lung disease & $10(5 \%)$ \\
Rheumatoid nodules & $14(7 \%)$ \\
Prednisone use & $103(51,5 \%)$ \\
Median dose of Prednisone last year (mg) & $2,34(2,84)$ \\
sDMARDs & \\
Methotrexate & $104(52 \%)$ \\
Leflunomide & $29(14,5 \%)$ \\
Hydroxycloroquine & $9(4,5 \%)$ \\
bDMARDs & $89(44,5 \%)$ \\
TNFi & $41(20,5 \%)$ \\
Abatacept & $15(7,5 \%)$ \\
IL6i & $22(11 \%)$ \\
RTX & $11(5,5 \%)$ \\
JAKi & $26(13 \%)$ \\
Baricitinib & $11(5,5 \%)$ \\
Tofacitinib & $15(7,5 \%)$ \\
DAS 28-ESR & $3,1(2,3,3,9)$ \\
SDAI & $7,85(4,04,13,41)$ \\
HAQ & $0,88(0,22,1,5)$ \\
RF (U/mL) & $51(15,164,25)$ \\
Anti-CCP (U/mL) & $173(22,340)$ \\
\hline
\end{tabular}

Patients showed higher intima-media (both right and left) thickness compared to controls $(p<0.006)$. Moreover it was also related to the disease duration and DAS28 score $(p<0.001)$ A higher plaque account was noted in $\operatorname{cases}(p<0.004)$ and it was also related to the disease duration $(p<0.001)$. 
Conclusion: RA implies a higher CV risk. Traditional CV risk factors explains only partially the global risk. These findings support that RA acts as an independent cardiovascular risk factor.

Disclosure of Interests: None declared

DOI: 10.1136/annrheumdis-2020-eular.6420

\begin{tabular}{|l|l}
\hline SAT0078 & SAFETY OF LOW DOSE METHOTREXATE (MTX) IN \\
HUMAN IMMUNODEFICIENCY VIRUS (HIV) INFECTION
\end{tabular}

A. Gunay ${ }^{1}$, A. Davidson ${ }^{1}$, I. Colmegna ${ }^{1}$, D. Lacaille ${ }^{2}$, H. Loewen ${ }^{3}$, M. Meltzer ${ }^{4}$, Y. Mengistu ${ }^{5}$, R. Scuccimarri ${ }^{1}$, Z. Yirsaw ${ }^{5}$, S. Bernatsky ${ }^{1}, \underline{\text { C. Hitchon }}{ }^{3} .{ }^{1}{ }^{M c}$ Gill University, Montreal, Canada; ${ }^{2}$ Arthritis Research Canada, Richmond, Canada; ${ }^{3}$ University of Manitoba, Winnipeg, Canada; ${ }^{4}$ Thomas Jefferson University, Philadelphia, United States of America; ${ }^{5}$ Addis Ababa University, Addis Ababa, Ethiopia

Background: Increased awareness of the efficacy of MTX in rheumatic disease is leading to more MTX use in patients from HIV endemic areas. While HIV related immunosuppression may contribute to improvement of some rheumatic diseases, immune reconstitution from highly active antiretroviral therapy (HAART) may lead to exacerbation or presentation of autoimmune disorders for which MTX therapy may be warranted. Most management guidelines for rheumatic disease do not address MTX use in the context of HIV.

Objectives: To systematically review the published literature on the safety of using MTX $\leq 30 \mathrm{mg}$ per week in HIV.

Methods: We searched CINAHL, Embase, Global, MEDLINE and World of Science databases (Jan 1990 to May 2018) for terms including 'methotrexate' and 'human immunodeficiency virus'. We also searched citations from review articles. Titles, abstracts or full manuscripts were screened independently by 2 reviewers to identify studies reporting HIV in patients taking MTX. Study quality was assessed using the McGill Mixed Methods Appraisal Tool (MMAT). Data was extracted on MTX and HIV adverse events (MTX toxicity, HIV viral load, CD4 count). Descriptive summaries are presented for studies providing outcomes in patients taking $\mathrm{MTX} \leq 30 \mathrm{mg}$ per week.

Results: After removing duplicates and studies not meeting criteria or not providing sufficient information, 42 of the 2714 identified reports were included (1 clinical trial, 2 cohort, 1 cross-sectional study, 38 case reports/case series). Most reports (81\%) originated from USA or Europe. Study quality was generally good with most studies fulfilling $50-100 \%$ of MMAT criteria. The randomized controlled trial (USA) assessing MTX on atherosclerotic disease in HIV showed that adverse events were more common in MTX versus placebo ( $12.8 \%$ vs $5.6 \%, p$ non-inferiority $<0.05$ ) and included infection, transient CD4 and CD8 drop, pulmonary toxicity, and death (1 attributed to MTX/HIV, 1 unrelated). One cohort study (South Africa) reported 43 RA patients on MTX who acquired HIV. In this cohort, RA generally improved despite only 5 individuals continuing MTX. No data on MTX adverse event rates was reported. One cohort study (USA) reported 13 HIV patients with myositis. One received MTX (with other immunosuppression) without MTX adverse effects but died due to AIDS. A cross-sectional study (France) of 43 HIV pts with autoimmune disease reported one patient on MTX (and other immunosuppression) developed an adverse event (cytopenia) compared to 5/33 patients not on MTX (cytopenia). The 38 case reports/series described 54 individuals with HIV receiving MTX. Of these studies, 27 (describing 42 subjects) reported on MTX adverse events and 35 (describing 46 subjects) reported on HIV adverse events. MTX adverse events developed in 29 subjects (hematologic 13, renal/hepatic 1, opportunistic infections 10, other events 2). HIV adverse events were noted in 23 subjects (Kaposi's sarcoma 4, CD4 decrease 16, HIV viral titer increase 4). Five deaths were reported (2 infection, 1 infection and wasting, 2 HIV related deaths). Most subjects also received corticosteroids or other immunosuppressants including biologics.

Conclusion: There remains limited data on the safety of low dose MTX in HIV. Surveillance for HIV is warranted for individuals on MTX who are at risk for acquiring HIV. Caution and careful monitoring for MTX toxicity, opportunistic infections and HIV state is suggested if MTX is used in the setting of HIV particularly if combined with other immunosuppression.

References:

[1] Clin Infectious Disease 2019:68

[2] J Rheumatology 2014:41

[3] Arthritis and Rheumatism 2003:49

[4] Medicine 2017:96

Acknowledgments : Funding from International League Against Rheumatism McGill University Global Health Scholar Awards

Disclosure of Interests: Alize Gunay: None declared, Anna Davidson: None declared, Ines Colmegna: None declared, Diane Lacaille: None declared, Hal Loewen: None declared, Michele Meltzer: None declared, Yewondwossen
Mengistu: None declared, Rosie Scuccimarri: None declared, Zenebe Yirsaw: None declared, Sasha Bernatsky: None declared, Carol Hitchon Grant/research support from: UCB Canada; Pfizer Canada

DOI: 10.1136/annrheumdis-2020-eular.2968

\begin{tabular}{|l|l}
\hline SAT0079 & FEATURES OF CLINICAL MANIFESTATIONS IN \\
PATIENTS WITH ACTIVE RHEUMATOID ARTHRITIS \\
IN THE PRESENCE OF SIGNS OF CENTRAL \\
SENSITIZATION
\end{tabular}

A. Karateev ${ }^{1}$, E. Filatova ${ }^{1}$, E. Pogozheva ${ }^{1}$, V. Amirdzhanova ${ }^{2}$, E. Nasonov ${ }^{2}$, A. Lila ${ }^{1}{ }^{1}$ Nasonova Research Institute of Rheumatology, Moscow, Russian Federation; ${ }^{2}$ Nasonova Research Institute of Rheumatology, Moscow, Russian Federation

Background: The presence of central sensitization (CS) is observed in $25-30 \%$ of patients with rheumatoid arthritis (RA). CS is associated with more severe pain, depression, and anxiety.

Objectives: To evaluate the effect of CS on activity indicators and clinical manifestations in patients with active RA.

Methods: The study group consisted of 60 patients with medium or high RA activity (DAS28 $\geq 3.2$ ), $75 \%$ female, age $54.5 \pm 17.8$ years, $82.1 \%$ RF "+", $75 \%$ ACPA "+." DN4 and PainDETECT questionnaires were used to identify CS signs. Signs of CS were detected in $43 \%$ of patients. Clinical parameters and indicators of disease activity in patients with RA CS "+" and CS "- "were compared.

Results: Groups of patients with RA CS "+" and CS "-" did not differ in age - 55.5 $[48.0 ; 67.5]$ and $54.0[40.0 ; 62.0], p=0.26$, body mass index $-24.54[22.6 ; 26.78]$ and $25.04[21.34 ; 29.665] \mathrm{kg} / \mathrm{m} 2, \mathrm{p}=0.64$, duration of illness: $6.5[2.5 ; 13.0]$ and $10.0[5.0 ; 16.5]$ years, $p=0.13$, level of $C$-reactive protein: $7.2[1.0 ; 23.4]$ and 8.1 [3.6; 24.3], $p=0.53$.

SC "+" patients had a higher level of pain on a visual analog scale, VAS (patient score) - 70.0 [60.0; 80.0] and $60.0[40.0 ; 70.0], P=0.01$; DAS28 - 5.33 [3.38; 6.42] and 4.5 [3.645; 5.4], $\mathrm{p}=0.04$; EQ-5D - 0.52 [0.02; 0.52] and 0.59 [0.52; 0.71], $\mathrm{p}=0.01$; anxiety level (Hads-T) $-8.0[7.0 ; 10.0]$ and 4.5 [2.5; 6.0], $p=0.001$ and depression (Hads-D) - $7.5[6.0 ; 10.5]$ and 5.0 [2.5; 7.5], $p=0.02$. The groups did not differ significantly in the values of SDAI, CDAl, and $\mathrm{HAQ}$, as well as in the assessment of health by the doctor (VAS) - $60.0[50.0 ; 70.0]$ and $60.0[50.0$; $60.0], p=0.42$.

Conclusion: The presence of SC is associated with more intense pain, anxiety, depression, and DAS28 activity. This should be taken into account when planning therapy, including deciding whether to "switch" DMARDs and prescribing antidepressants and anticonvulsants.

Disclosure of Interests: None declared

DOI: 10.1136/annrheumdis-2020-eular.3954

\section{SAT0080 COMPARATIVE ANALYSIS OF FRAGILITY FRACTURE IN PATIENTS WITH ELDERLY ONSET RHEUMATOID ARTHRITIS AND YOUNG ONSET RHEUMATOID ARTHRITIS}

P. Kozhevnikova ${ }^{1}$, I. Dydykina ${ }^{1}$, P. Kovalenko ${ }^{1}$, A. Lila ${ }^{1}{ }^{1}$ V.A. Nasonova

Research Institute of Rheumatology, Moscow, Russian Federation

Background: Rheumatoid arthritis (RA) is a chronic autoimmune disease, characterized by erosive arthritis and systemic organ involvement. Chronic inflammation, long RA disease duration, decreased physical activity, immobilization, glucocorticoids use lead to local (periarticular osteoporosis) and generalized loss of bone tissue, decrease in bone mineral density, contravention of microarchitectonics and increased risk of fragility (low-energy) fractures. The structure and density of bone tissue at elderly onset RA, in addition to the above factors, are affected by comorbid diseases, sex steroids level decrease and molecular changes in bone tissue, specifically attributed to aging, followed by increased bone resorption. Fractures reduce the quality of life, have a negative impact on the course of the underlying and concomitant diseases.

Objectives: Compare frequency of fragility fracture in patients with elderly onset rheumatoid arthritis and young onset rheumatoid arthritis.

Methods: We included 474 patients with RA diagnosed at 25- 78 years old and fulfilled the American College of Rheumatology (formerly American Rheumatism Association) classification criteria for RA revised in 1987. The patients were divided into two groups depending on age at the RA-onset: The first group (group I) included 217 patients with young onset RA (at 25 to 44 years), second group (group II) included 66 patients with elderly onset RA (aged $\geq 60$ years). The distribution of patients into groups was consistent with the age classification of the World Health Organization. In total, it was selected 283 RA patients. The mean age in group I was 50.4 years, in group II - 71.2 years. The mean age at the onset 